\title{
Marina Franco, \\ El final del silencio. Dictadura, sociedad y derechos humanos en la transición
}

(Argentina, 1979-1983),

Buenos Aires, FCE, 2018, 411 páginas

El campo de la historia argentina reciente, que ha tenido en la investigadora Marina Franco a una de sus principales figuras impulsoras, se ha desarrollado vigorosamente en los últimos años. Cada vez son más los estudios que, a partir de abordajes transversales que entrecruzan la historia cultural y política, la sociología, la ciencia política y los estudios sobre memoria, buscan comprender cuestiones del pasado próximo, y en un lugar destacado los procesos de violencia política y represión estatal ocurridos (aunque no solo) en el ámbito local. El final del silencio. Dictadura, sociedad y derechos humanos en la transición (Argentina, 1979-1983), último libro de la historiadora, es un trabajo que surge de ese diálogo de la historia con otras disciplinas y que tiene como foco de indagación principal el surgimiento del problema de la represión como asunto público en la etapa final de la última dictadura argentina.

Si bien el foco principal está en los años postreros de la dictadura, el libro propone un recorte temporal más amplio, que comienza con la visita de la Comisión Interamericana de Derechos Humanos (CIDH) en 1979 y termina con las elecciones de 1983. A través de diversas fuentes - la ya clásica prensa escrita de la época como
Clarín y La Nación, el no tan explorado Tiempo Argentino, entrevistas personales y archivos orales de segunda mano-, Franco descifra los vínculos que se tejen entre la sociedad y el autoritarismo a partir de un juego de fuerzas en el que distintos actores de la escena pública atribuyen determinados sentidos al tema de la represión. Así, los partidos políticos, los medios de prensa, la Iglesia católica, el Poder Judicial y las organizaciones de Derechos Humanos se imbrican en un escenario complejo de posiciones indeterminadas y hasta cambiantes. Como plantea la autora, el problema de la violencia estatal no se vuelve un hecho a visibilizar, denunciar y juzgar de manera automática, sino que se vincula con las diferentes dimensiones que fue adquiriendo el derrumbe castrense. En ese sentido, desde el comienzo el libro hace explícito su argumento principal: "la emergencia del tema fue en buena medida (aunque no por completo) una consecuencia de la deslegitimación y el derrumbe del régimen militar, y no al revés, como suele creerse" (p. 31). En otras palabras, el rechazo ético y humanitario generalizado de la represión estatal no ocurrió tanto por su especificidad propia, sino que dependió de otros factores de deslegitimación, vinculados a diversos planos (militar, político, económico y social).

El final del silencio se estructura en cuatro capítulos, ordenados a partir de un criterio temporal y analítico. En el primero de ellos, "La legitimidad de la represión y la deslegitimación del régimen", Franco se detiene en los años 1979 y 1980 y ubica la visita de la CIDH como el primer momento donde se difunden pública y oficialmente las violencias del régimen. Sin embargo, sostiene el apartado, la recepción del informe en plena vigencia de la "lucha antisubversiva" indica un clima general a favor de las Fuerzas Armadas. La autora reconstruye detenidamente el modo en que, a pesar de que los crímenes comenzaban a ser visibles tanto en el informe de la CIDH como fragmentariamente en la prensa, la cuestión de la violencia estatal no llegaba a configurar un problema público. Más bien al contrario, sirvieron para fortalecer las bases de apoyo del gobierno castrense en la tarea política de garantizar el orden social. En este punto, se pone de manifiesto cómo, tras la publicación del informe, la Junta Militar emprende una seguidilla de movimientos tendientes a cerrar la etapa previa y apostar a una convergencia cívico-militar que garantice la continuidad del proyecto dictatorial a partir de 
un horizonte político: entre ellos, pueden mencionarse las "Bases políticas de las Fuerzas Armadas para el Proceso de Reorganización Nacional", la conformación del Movimiento de Opinión Nacional, el llamado "contrainforme de la CIDH", las "Premisas básicas no negociables", etc. Ubicadas en ese marco, las denuncias eran justificadas por circunstancias inevitables que eludían toda responsabilidad gubernamental. Simultáneamente, el capítulo reconstruye el progresivo proceso de deslegitimación del régimen, no asociado a la cuestión humanitaria sino al plan económico y sus consecuencias sociales. La violencia relatada en las todavía esporádicas noticias era percibida por los actores de la época no como una evidencia empírica capaz de ser articulada bajo una denuncia, sino solamente, dice Franco, como una presencia.

"La ilusión de la apertura y la búsqueda del cierre", segundo capítulo de El final del silencio, se detiene en el momento pre-Malvinas (19811982) como un período con densidad propia. Comenzando por la presidencia de Roberto Viola, la autora retrata las inconsistencias internas del régimen en lo que respecta a las condiciones del estatuto de partidos. Problematizando conceptos como "transición argentina" y "derechos humanos", Franco repasa los posicionamientos que tuvieron los diferentes actores en esta etapa. El nuevo ciclo inaugurado por Viola permite entrever algunas señales (aunque todavía escasas) que hacen suponer un crecimiento de las voces denunciantes, pero quizá sea precisamente el carácter limitado de las mismas lo que permite sintetizar un cuadro de época. Salvando excepciones (como el caso del Buenos Aires Herald, La Opinión o las propias organizaciones humanitarias), la denuncia de la represión no tenía un papel central en los discursos que circulaban en 1982 entre los partidos políticos, la Iglesia católica y la prensa, tanto "masiva" como "no hegemónica": mientras que los sectores católicos y la naciente Multipartidaria se eslabonaban bajo la advocación de la reconciliación nacional, ni siquiera las voces consideradas más antiautoritarias (tal como la revista Humor) hacían de las violaciones de derechos humanos el eje principal de sus intervenciones. En cambio, para entonces "el problema de los desaparecidos" fue adquiriendo una relativa autonomía en los debates públicos. Si para 1981 ese tópico aún era un elemento político sin demasiado peso propio, hacia 1982 la cuestión asumía mayor espesor.

El tercer capítulo, "La eclosión antidictatorial", busca iluminar ciertas zonas grises en lo que respecta a la significación pública de la guerra de Malvinas. Lejos de situarla como un parteaguas que modificó drásticamente los sentidos sobre la violencia, Franco inteligentemente ubica la derrota bélica en el contexto de la crisis económica, el clima antimilitar y en lo que denomina "el fin de las Fuerzas Armadas victoriosas en la guerra interna". El final del silencio muestra que en este período la búsqueda por cerrar el tema de la violencia estatal por parte de la institución militar también involucró a los dirigentes políticos, a la Iglesia católica y a la prensa. Muchas de estas voces, al tiempo que exigían "información y verdad", dejaban sin cuestionamiento la "lucha antisubversiva". Mientras, los organismos de derechos humanos profundizaban una dirección de involucramiento de los medios de comunicación y el Poder Judicial en función de visibilizar sus reclamos. El capítulo además recorre las manifestaciones de estos organismos en la escena pública, subrayando, por caso, que las explicaciones que exigían las Madres de Plaza de Mayo no perseguían el mismo objetivo que las del resto de los actores públicos. De "Aparición con vida" en el año 1981, la consigna pasó a ser "Juicio y castigo a los culpables" en 1982. Sin embargo, nos recuerda Franco, este último vocablo carecía todavía de un sentido homogéneo y no contaba con gran legitimidad política. El libro muestra que, en la medida en que aumentaba el clima antidictatorial y opositor, el gobierno castrense emprendió una estrategia de clausura y autoconfirmación, basada en un conjunto de acciones psicológicas encaminadas a evitar un "rebrote subversivo". Esta vez, plantea la autora, la subversión era identificada con los organismos de derechos humanos dentro y fuera del país. Consecuentemente, la reafirmación de ese marco de sentido se cristalizaría más tarde en el llamado "Documento final", en abril de 1983.

En el último capítulo, "Las opciones se estrechan", Franco 
se concentra en el año 1983, comenzando por el Documento final y las disidencias internas en torno a la ley de la autoamnistía hasta llegar a las elecciones de octubre. Ilumina ciertas dimensiones del juego de fuerzas, como el hecho de que los partidos políticos (a diferencia de los organismos de derechos humanos) llegaron a ser consultados en torno a la ley de autoamnistía. Asimismo, el capítulo examina los reacomodamientos del Poder Judicial y su alejamiento de la Junta en un momento en que la institución militar buscaba protegerse judicialmente. ¿Cómo se volvieron las banderas de justicia e investigación sobre los crímenes dictatoriales un horizonte capaz de encarnar en un proyecto de gobierno?, se pregunta Franco. Si hasta entonces las consignas de "juicio y castigo" no tenían un sentido unívoco, el libro muestra que en este momento la exigencia de justicia adquiere un carácter más orgánico. Sin embargo, como se desprende del análisis, existía un hiato ineliminable entre el rechazo social de la autoamnistía y el reclamo de justicia por los crímenes. Para 1983, explica la autora, la prensa continuaba hablando en términos hegemónicos de "violencia subversiva". Sin embargo, algo tuvo que haber cambiado -acierta- para que algunos discursos públicos del último año de la dictadura tuviesen un mayor énfasis en los derechos humanos. De allí que la figura de Raúl Alfonsín aparezca acaso como un símbolo de distinción entre los demás candidatos de la contienda electoral. Lejos estaban los argentinos en 1983 de presenciar la emergencia de un nuevo paradigma sobre los derechos humanos. Como afirma la autora, ese proceso apenas comenzaba.

El libro de Franco reconstruye los pliegues de un final del silencio que, al margen de lo que la memoria social contemporánea evoca, demoró en llegar. Sin duda, un punto a destacar de esta exhaustiva investigación es que desestabiliza ciertas ideas comunes acerca del período, como aquella que sostiene que amplios sectores sociales ignoraban el tema de la represión (el remanido "no sabíamos nada"). Después de todo, como observa la autora, el hecho de que las denuncias por la represión hayan tenido visibilidad de manera temprana no se tradujo en un cambio radical en la forma de pensar lo sucedido. Con respecto a esto, cabría preguntarse si dentro del valioso menú de actores que ella considera, los provenientes de la esfera transnacional pudieron tener (además de la visita de la CIDH) algún peso en la configuración de los sentidos públicos sobre la dictadura. Otra cuestión a subrayar es que el texto se aproxima a las significaciones sobre el horror a partir de un continuo ejercicio de autorreflexividad y vigilancia epistemológica que en ningún momento deja de lado la pregunta por las condiciones de producción historiográficas. En síntesis, $E l$ final del silencio es un relato acerca de cómo los derechos humanos y el reclamo por los desaparecidos se volvieron un discurso público dominante, pero también funciona como una caja de herramientas tanto metodológica como política que nos interroga acerca de qué manera y por qué narramos la historia. La insistencia de Franco en reconstruir una parte de la historia de las violencias extremas sin una mirada complaciente no es solo una propuesta sofisticada para pensar el pasado reciente argentino, sino también un imperativo actual, necesario e inaplazable.

\section{Paola Benassai IIGG / Universidad de Buenos Aires}

